\title{
Does isolated and combined acute supplementation of caffeine and carbohydrate feeding strategies modify 10-km running performance and pacing strategy? A randomized, crossover, double-blind, and placebo-controlled study
}

\author{
Francisco A. Manoel' ${ }^{1}$ Ana C. P. Kravchchyn², Diego Hilgemberg Figueiredo ${ }^{3}$, Diogo Hilgemberg Figueiredo ${ }^{3}$, \\ Fabiana A. Machado ${ }^{3,4}$
}

'Department of Physical Education. Cesumar University. Maringá - PR. Brazil. Brazil. ${ }^{2}$ Federal University of São Paulo. UNIFESP. Brazil. ${ }^{3}$ Associate Post-Graduate Program in Physical Education UEM/UEL. Department of Physical Education. State University of Maringá. Maringá - PR. Brazil. ${ }^{4}$ Post-graduate Program of Physiological Sciences. Department of Physiological Sciences. State University of Maringá. Maringá - PR. Brazil.

doi: 10.18176/archmeddeporte.00042

Recibido: 01/09/2020

Aceptado: 25/02/2021

Key words:

Ergogenic aid. Endurance. Runners. Physical endurance.

\section{Summary}

Background: Long distance practice running are growing and nutritional ergogenic are commonly used as a potential aid in final training and competition performance. Caffeine (CAF) and carbohydrates (CHO) are among the most commonly used supplements due to their expected ergogenic properties that can optimize energetic systems. The objective of this study was to examine potential changes in 10-km running performance with acute isolated and combined CAF and CHO supplementation. Material and method: Fifteen recreational endurance-trained runners performed four 10-km running performance on an official athletic track (400 m) under four supplementation conditions: placebo and placebo (PLA+PLA), placebo and caffeine $(\mathrm{PLA}+\mathrm{CAF})$, placebo and carbohydrates $(\mathrm{PLA}+\mathrm{CHO})$, caffeine and carbohydrates (CAF+CHO). $\mathrm{CAF}$ and $\mathrm{CHO}$ supplementation consisted of capsules of $6 \mathrm{mg} \mathrm{kg}^{-1}$ and $8 \% \mathrm{CHO}$ solution $\left(1 \mathrm{~g}^{\mathrm{kg}}{ }^{-1}\right)$ respectively, ingested 60 and 30 minutes before the performance tests. Placebo was obtained through empty capsules for CAF and juice for $\mathrm{CHO}$ without sugar (Clight $\left.{ }^{\circledR}\right)$. During each trial running speed to calculate $10-\mathrm{km}$ mean velocity (MV) and maximum heart rate $\left(\mathrm{HR}_{\text {max }}\right)$ were analyzed.

Results: There was a difference in the pacing strategy adopted by the runners with higher MV during the initial phase for $\mathrm{PLA}+\mathrm{CAF}$ and $\mathrm{CAF}+\mathrm{CHO}$ groups and in the final phase for PLA+CHO. However, there was no statistically significant difference in 10-km running performance between the conditions, as well as for $\mathrm{HR}_{\text {max }}$

Conclusions: The use of acute, isolated and combined $\mathrm{CAF}+\mathrm{CHO}$ supplementation had influence in the pacing strategy, but no in 10- $\mathrm{km}$ final performance, of recreational runners.

La suplementación aguda, aislada y combinada de cafeína y carbohidratos como estrategias de alimentación cambia el rendimiento y un ritmo de carrera de 10-km? Un estudio aleatorizado, cruzado, doble ciego, controlado con placebo

\section{Resumen}

Introducción: Las carreras de larga distancia están creciendo y los ergógenos nutricionales se usan comúnmente como una ayuda potencial en el entrenamiento final y el rendimiento en competición. La cafeína (CAF) y los carbohidratos (CHO) se encuentran entre los suplementos más utilizados debido a sus propiedades ergogénicas que pueden optimizar los sistemas energéticos. El objetivo de este estudio fue examinar posibles cambios en el rendimiento de carrera de 10-km con suplementación aislada aguda y combinada de CAF y CHO.

Material y método: Quince corredores recreativos realizaron cuatro carreras de 10-km en una pista deportiva oficial (400 m) bajo cuatro condiciones de suplementación: placebo y placebo (PLA + PLA), placebo y cafeína (PLA + CAF), placebo y carbohidratos (PLA + CHO), cafeína y carbohidratos (CAF + CHO). La suplementación con CAF y CHO consistió en cápsulas de $6 \mathrm{mg} \cdot \mathrm{kg}^{-1}$ y solución de $\mathrm{CHO}$ al $8 \%\left(1 \mathrm{~g} \cdot \mathrm{kg}^{-1}\right)$ respectivamente, ingeridas 60 y 30 minutos antes de las carreras. El placebo se obtuvo usando cápsulas de CAF vacías y jugo sin azúcar para CHO (Clightø). Durante cada carrera, se analizó la velocidad de carrera para calcular la velocidad promedio de 10-km (VP) y la frecuencia cardíaca máxima ( $F C_{\text {máx }}$.

Resultados: Hubo una diferencia en la estrategia de carrera adoptada por los corredores con la VP más alta durante la fase inicial para los grupos PLA + CAF y CAF + CHO y en la fase final para PLA + CHO. No hubo diferencias estadísticamente significativas en el rendimiento de carrera de 10-km entre las condiciones, así como en la $\mathrm{FC}_{\text {máx }}$

Palabras clave: Ayuda ergogénica. Resistencia. Corredores. Desempeño atlético.
Conclusiones: El uso de suplementos agudos, aislados y combinados de CAF + CHO influyó en la estrategia de carrera, pero no en el rendimiento final de 10-km en corredores recreativos

Correspondencia: Fabiana A. Machado

E-mail: famachado_uem@hotmail.com,famachado@uem.br 


\section{Introduction}

Scientific research's designed to assess physiological and performance parameters responses with the aim of improve professional and recreational running performance are growing due to the increase in long distance running practices ${ }^{1,2}$. In this context, nutritional ergogenic are commonly used as potential aid in final training and competition performance. Among the possible nutritional supplements that are commonly used, the isolated and combined caffeine (CAF) and carbohydrates $(\mathrm{CHO})$ feeding strategies are the most ergogenic resources used in endurance exercise ${ }^{2-4}$. Previous studies have indicated that $\mathrm{CHO}$ ingestion has a positive effect on endurance performance ${ }^{5,6}$. This effect have been attributed to the maintenance of plasma glucose concentrations and, high rates of $\mathrm{CHO}$ oxidation late in exercise when muscle and, liver glycogen level are low ${ }^{5}$.

Additionally, CAF has been widely used as an ergogenic aid to increase physical performance ${ }^{7,8}$, and is the most frequently aid used by athletes for it influence in the central nervous system (CNS) ${ }^{9}$, optimize skeletal muscle function and reduce the perception of pain ${ }^{10}$. Cox et al. ${ }^{7}$ demonstrated an increased endurance performance ( 3.1\% in time trial) in twelve highly trained cyclists after the ingestion of $6 \mathrm{mg} \cdot \mathrm{kg}^{-1}$ of $C A F$, independent of the time it was ingested (i.e., pre-exercise, each 20 minutes during exercise and, between 100 and 120 minutes during exercise), which the authors hypothesized to be related to an increase in plasma free fat acids (FFA) concentration and to an increase in fat oxidation, both from blood-borne and intramuscular stores during the exercise. However, few studies have investigated the effects of CAF ingestion prior to exercise performance in runners, which still is restrict to shorter running distances ${ }^{11,12}$.

Previous studies have also investigated the potential effect of the combination of these two supplements, which has demonstrated greater improvements in endurance performance when they are coingested than either independently ${ }^{13}$, possibly due to CAF increasing the rate at which $\mathrm{CHO}$ can be absorbed ${ }^{14}$. The absorption of glucose in the intestine regulates the amount that it is delivered into circulation, becoming saturated at higher glucose ingestion rates, which may further prevent absorption limiting $\mathrm{CHO}$ availability to circulation ${ }^{14}$. CAF consumption could then significantly increase intestinal glucose absorption increasing $\mathrm{CHO}$ availability and increase exogenous $\mathrm{CHO}$ oxidation during exercise ${ }^{14}$. However, some studies that have evaluated the potential effect of the ingestion of CAF combined with $\mathrm{CHO}$ on endurance performance than that of $\mathrm{CHO}$ alone have been equivocal? .

Nonetheless it is not well established whether their combination can produce different results from isolated use during physical exercise due to contradictory results reported by studies using different doses, types and time management in addition to exercise protocols with different energy requirements ${ }^{3,15}$. Moreover, few studies have found isolated and combined effect of CAF and $\mathrm{CHO}$ in running ${ }^{16}$, however the researchers investigated the independent and synergistic ability of $\mathrm{CHO}$ and $\mathrm{CAF}$ mouth rinsing to improve intermittent running performance. However, it is currently unknown whether the acute isolated and combined supplementation of caffeine and carbohydrate feeding strategies influences endurance performance during running.
Therefore, the aim of this study was to verify potential changes in 10-km running performance with acute isolated and combined CAF and $\mathrm{CHO}$ supplementation, and in addition, to verify the effects of both supplementations on the pacing strategy and other associated physiological variables. Our hypothesis is that the combined and isolated use of these two supplements modifies 10-km running performance as well as the pacing strategy, but with larger changes observed when these supplementations are combined.

\section{Material and method}

The sample size was calculated with the software $\mathrm{G}^{*}$ Power version 3.1.9.2 (Düsseldorf, Germany), considering an effect size of 0.25, power of $80 \%$ and alpha of 0.05 for the primary outcome performance. The priori power analysis revealed a minimal sample of 15 participants. Fifteen male, recreational, endurance-trained runners (age $25.2 \pm 2.8$ years old, height $180.0 \pm 6.0 \mathrm{~cm}$, body mass $79.9 \pm 7.7 \mathrm{~kg}$, body mass index (BMI) $24.6 \pm 1.9 \mathrm{~kg} \cdot \mathrm{m}^{-2}$, body fat $14.2 \pm 2.9 \%$ and basal metabolic rate (BMR) $2185.7 \pm 232.0 \mathrm{kcal}^{\prime} \cdot \mathrm{day}^{-1}$ ) from regional and local standard level with a minimum of 2 years of training experience and a training volume of at least $20 \mathrm{~km} \cdot \mathrm{wk}^{-1}$ (training experience $4.1 \pm 3.5$ years, frequency $2.7 \pm$ 1.4 days $\cdot \mathrm{wk}^{-1}$ and distance between 60 and $70 \mathrm{~km} \cdot \mathrm{wk}^{-1}$ ) volunteered to take part in this study. The 10-km running times of the participants were between 35 and $60 \mathrm{~min}$, with a pace between 10 and $17 \mathrm{~km} \mathrm{~h}^{-1} \approx 44$ and $75 \%$ of the World record). Prior to testing, all participants provided a proper written informed consent and The University Ethics Committee approved the experimental protocol (\#41915/2012).

\section{Experimental overview}

In a randomized, crossover, double-blinded and placebo-controlled design, each participant performed four 10-km running performance under four supplementation conditions in alternate order: placebo and placebo (PLA+PLA), placebo and caffeine (PLA+CAF), placebo and carbohydrate $(\mathrm{PLA}+\mathrm{CHO})$, caffeine and carbohydrate $(\mathrm{CAF}+\mathrm{CHO})$. The interval between each performance was at least 72 to $96 \mathrm{~h}$; participants were instructed to avoid eating $3 \mathrm{~h}$ before the tests, to abstain from CAF and alcohol, and to refrain from strenuous exercise also for $24 \mathrm{~h}$ before. All tests were performed on a 400 m official outdoor track at the same time of the day to minimize the influence of circadian variance. Participants received a dietary control that was made during all protocol for CAF and blood glucose levels control.

\section{0-km performance}

Participants undertook four 10-km running performance on the track field $(400 \mathrm{~m})$ outdoor without the presence of opponents or another competitor on the track being all preceded by a self-determined warm-up of $10 \mathrm{~min}$. To determine 10-km running performance, participants were asked to complete the distance as quickly as possible on the track field. Participants freely choose their pacing strategy during the performance being then blinded for pacing through the test and the time was hand-timed every $400 \mathrm{~m}$ to the nearest second. The overall mean velocity (MV) for each trial was calculated by dividing the total 
distance covered by the trial duration. Additionally, partial MV were calculated in three phases: (1) start (first $400 \mathrm{~m})$, (2) middle (400-9.600 $\mathrm{m}$ ) and (3) end (last $400 \mathrm{~m}$ ), as previously reported ${ }^{1,17}$. Mineral water was provided ad libitum in cups throughout performances, so that runners could hydrate themselves as they were used to do in long-distance races. Heart rate was recorded each trial (Polar ${ }^{\oplus S} 800$ sd, Kempele, Finland) to calculate submaximal heart hate $\left(\mathrm{HR}_{\text {submax }}\right)$ and maximal heart hate $\left(H R_{\max }\right)$ was defined as the highest $H R$ value recorded during the test.

\section{Supplementation protocol}

The CAF capsules doses were administrated for each participant in the amount of $6 \mathrm{mg} \mathrm{kg}^{-1}, 60$ minutes before the test ${ }^{18}$. The $8 \% \mathrm{CHO}$ solution was offered in maltodextrin powder form with $1 \mathrm{~g} \cdot \mathrm{kg}^{-1}, 30$ minutes before the test. The PLA effect was obtained through empty capsules with the same characteristics of form, weight and color as CAF. The PLA for maltodextrin was juice by $\mathrm{Clight}^{\circledR}$ without sugar $(0 \mathrm{~g}$ carbohydrates) and with the same flavor ${ }^{6}$.

\section{Statistical analyses}

The data were analyzed using the Statistical Package for the Social Sciences 13.0 software (SPSS ${ }^{\circledR}$ Inc., Chicago, IL, USA). The Shapiro-Wilk test was used to verify the data distribution normality and the data are presented as mean \pm standard deviation (SD). The variables were compared using a two-way analysis of variance (Anova) with repeated measures, with condition (PLA+PLA, PLA+CAF, PLA+CHO and
$\mathrm{CAF}+\mathrm{CHO})$ and distance $(0-0.4 \mathrm{~km}, 0.4-9.6 \mathrm{~km}$ and $9.6-10-\mathrm{km})$ for $\mathrm{MV}$ and HR, as factors followed by the Bonferroni post hoc test. The sphericity assumption was verified through the Mauchly's test and, where violations occurred, degrees of freedom were corrected using Greenhouse-Geisser estimates of sphericity. Statistical significance was set at $P<0.05$. Comparisons were confirmed through graphical error to avoid type I error. In addition, a Bayesian Anova was used to determine changes in MV and HR as dependent variables, condition and distance as fixed factors., using the software JASP® (University of Amsterdam, Department of Psychology \& Psychological Methods unit), considering BF10 as Bayes Factor and Bayes Factor inclusion $\left(\mathrm{BF}_{\text {inc }}\right)$ to analyze the effects for it model.

\section{Results}

The variables time 10-km, MV 10-km and HRmax obtained during 10-km running performance in PLA +PLA, PLA+CAF, PLA+CHO and $\mathrm{CAF}+\mathrm{CHO}$ supplement conditions are presented in Table 1. These variables did not differ between supplement conditions.

The individual results of the 10-km running performance in each of the conditions are presented in Figure 1. Although there was no statistical difference in 10-km performance between conditions $(P=0.981)$ individual analysis shown that of the 15 participants who completed the experimental protocol, 7 presented a shorter time in PLA+CAF condition (Figure $1 \mathrm{~A}$ ); 8 in the PLA+CHO condition (Figure 1 B) and 9 in the $\mathrm{CHO}+\mathrm{CAF}$ condition than in the PLA condition (Figure $1 \mathrm{C}$ ).

Table 1. Comparison of $10 \mathrm{~km}$ final time, $\mathrm{MV}$ and $\mathrm{HR}_{\max }$ obtained in 10-km running performance between PLA, PLA+CAF, PLA+CHO and $\mathrm{CAF}+\mathrm{CHO}(\mathrm{n}=15)$.

\begin{tabular}{lccccc}
\hline Variables & PLA & PLA+CAF & PLA+CHO & CAF+CHO & F \\
\hline Time $10 \mathrm{~km}(\mathrm{~min})$ & $50.0 \pm 3.9$ & $50.0 \pm 4.7$ & $50.0 \pm 5.2$ & $49.9 \pm 5.0$ & 0.05 \\
$\mathrm{MV} \mathrm{10} \mathrm{km}\left(\mathrm{km} \cdot \mathrm{h}^{-1}\right)$ & $12.1 \pm 1.0$ & $12.1 \pm 1.3$ & $12.2 \pm 1.5$ & $12.2 \pm 1.4$ & 0.21 \\
$\mathrm{HR}_{\max }(\mathrm{bpm})$ & $186 \pm 8.1$ & $186 \pm 8.8$ & $185 \pm 8.0$ & $189 \pm 9.4$ & 1.27 \\
\hline
\end{tabular}

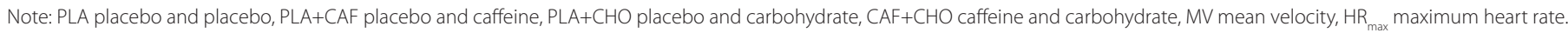
$P<0.05$

Figure 1. Mean and individual results of the 10-km running performance in each of the conditions. PLA vs PLA+CAF (A), PLA vs PLA + CHO (B), PLA vs CHO + CAF (C). Dash line represents the mean values.

A

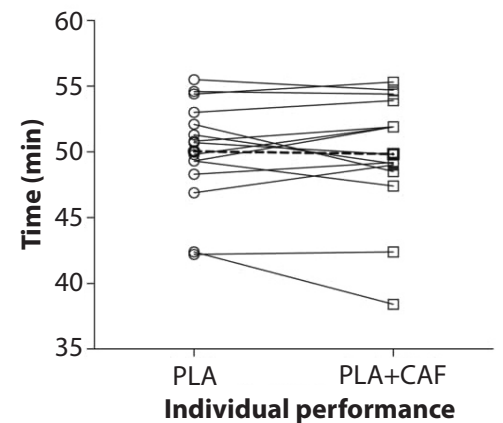

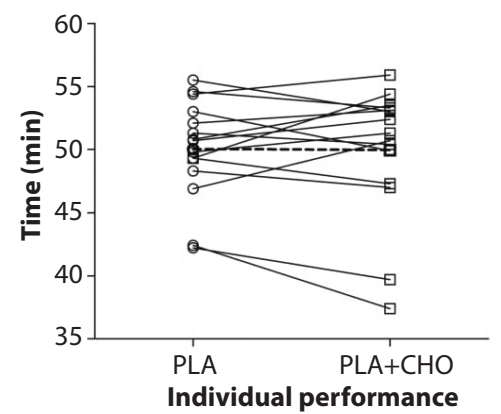

C

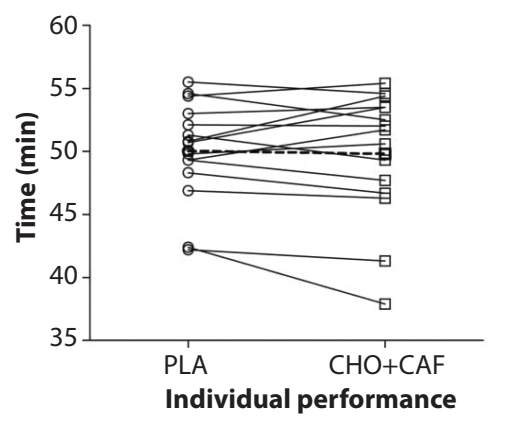

${ }^{*} P<0.05$ in relation placebo condition. 
Figure 2. Running pacing strategy adopted by the participants of the present study for the PLA, PLA+CAF, PLA+CHO and CAF+CHO condition, during $10 \mathrm{~km}$ running performance.

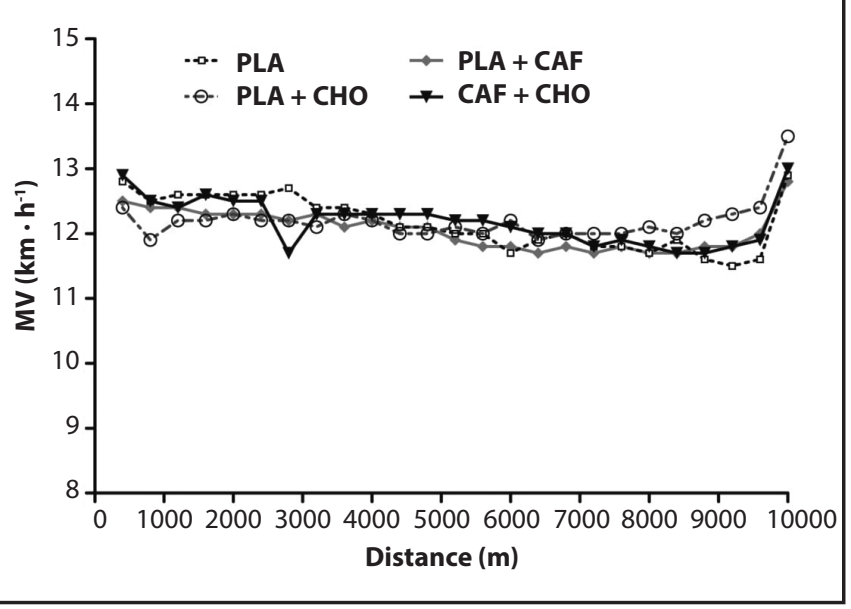

Figure 2 shows the variation of MV according to distance, which demonstrate that the participants used the "constant" running pace as a test strategy in PLA condition. In the conditions PLA+CAF and CAF+CHO a "negative" strategy was observed, and in PLA+CHO condition a "J" strategy was observed.

Figure $3 \mathrm{~A}$ shows the MV in each phase (start, middle and end phase) of the 10-km running performance. There was no significant difference between conditions for MV during each phase of the 10-km running performance. In addition, there was a significant main effect for MV during each phase within group for the 10-km running performance. Post-hoc analysis showed that there was a significant difference between the start phase than that in the middle phase for the PLA-CAF group $\left(12.8 \pm 1.6 \mathrm{~km} \cdot \mathrm{h}^{-1}\right.$ vs. $\left.12.1 \pm 1.2 \mathrm{~km} \cdot \mathrm{h}^{-1} ; P=0.017\right)$. For the $\mathrm{CAF}+\mathrm{CHO}$ group, the MV in the middle phase were lower than the initial phase $\left(12.8 \pm 1.6 \mathrm{~km} \cdot \mathrm{h}^{-1}\right.$ vs. $\left.12.1 \pm 1.2 \mathrm{~km} \cdot \mathrm{h}^{-1} ; P=0.017\right)$, with no significant difference between the end phase $\left(13.0 \pm 1.6 \mathrm{~km} \cdot \mathrm{h}^{-1}\right)$ when compared to the middle $\left(12.1 \pm 1.2 \mathrm{~km} \cdot \mathrm{h}^{-1}\right)$ and start phase $\left(12.8 \pm 1.6 \mathrm{~km} \cdot \mathrm{h}^{-1}\right)$. For the PLA-CHO group, the MV in the start phase were lower than that in the end phase $\left(12.4 \pm 1.7 \mathrm{~km} \cdot \mathrm{h}^{-1} \mathrm{vs} .13 .5 \pm 1.6 \mathrm{~km} \cdot \mathrm{h}^{-1} ; P=0.03\right)$, and the middle phase were lower than the end phase $\left(12.1 \pm 1.4 \mathrm{~km} \cdot \mathrm{h}^{-1} \mathrm{vs}\right.$. $\left.13.5 \pm 1.6 \mathrm{~km} \cdot \mathrm{h}^{-1} ; P=0.001\right)$. In addition, for the CAF-CHO group there was a significant difference for MV during the start phase compared to the middle phase $\left(12.9 \pm 1.2 \mathrm{~km} \cdot \mathrm{h}^{-1} \mathrm{vs} .12 .1 \pm 1.4 \mathrm{~km} \cdot \mathrm{h}^{-1} ; P=0,019\right)$. Nonetheless, there was no difference for MV during each phase of the 10-km running performance for PLA group. In addition, the Bayesian analysis demonstrated that when compared to the Null model, phase is a better model $\left(\mathrm{BF}_{10}=12.769 ; \mathrm{BF}_{\text {incl }}=8.531\right)$, but when the condition and the interaction between condition and phases are analyzed the Null model was considered better $\left(\mathrm{BF}_{10}=0.010 ; \mathrm{BF}_{\text {incl }}=0.025\right.$ for condition; $\mathrm{BF}_{10}=0.463 ; \mathrm{BF}_{\text {incl }}=0.006$ for interaction).

Figure $3 \mathrm{~B}$ shows the $\mathrm{HR}_{\text {submax }}$ during each phase of the $10-\mathrm{km}$ running performance. There were no statistical differences between groups for each phase of the 10-km running performance. Within group analyses demonstrated that there were statistical differences between HR during each phase $(P<0.001)$. Post hoc analyses demonstrated that there was an increase in HR during each phase of the 10-km running performance for all groups $(P<0.001)$. The Bayesian analysis demonstrated that when compared to the Null model, phase $\left(\mathrm{BF}_{10}<0.001\right.$; $\left.\mathrm{BF}_{\text {incl }}<0.001\right)$, condition $\left(\mathrm{BF}_{10}<0.001 ; \mathrm{B}_{\text {Fincl }}=0.208\right)$, and the interaction $\left(\mathrm{BF}_{10}<0.001 ; \mathrm{BF}_{\text {incl }}=0.034\right)$ were not considered better models.

\section{Discussion}

The aim of this study was to verify potential changes in 10-km running performance with acute isolated and combined $\mathrm{CAF}$ and $\mathrm{CHO}$ supplementation, and in addition, to verify the effects of both supplementations on the pacing strategy and other associated physiological variables. The main finding was that acute isolated and combined CAF and $\mathrm{CHO}$ supplementation did not modify the final 10-km running performance, with differences only in pacing strategy, partially confirming our initial hypothesis.

Figure 3. Mean velocity (A), Heart rate (B) during the different phases adopted by the participants of the present study for the PLA, PLA+CAF, $\mathrm{PLA}+\mathrm{CHO}$ and $\mathrm{CAF}+\mathrm{CHO}$ condition.

A

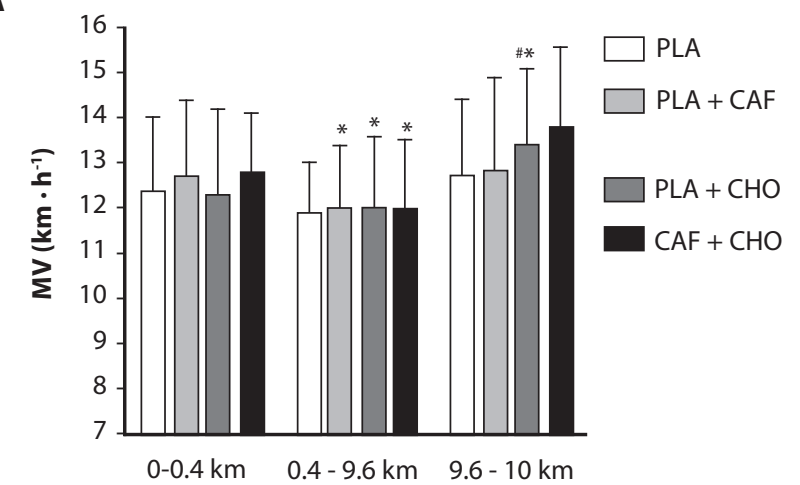

Phase of the $10 \mathrm{~km}$ running performance
B

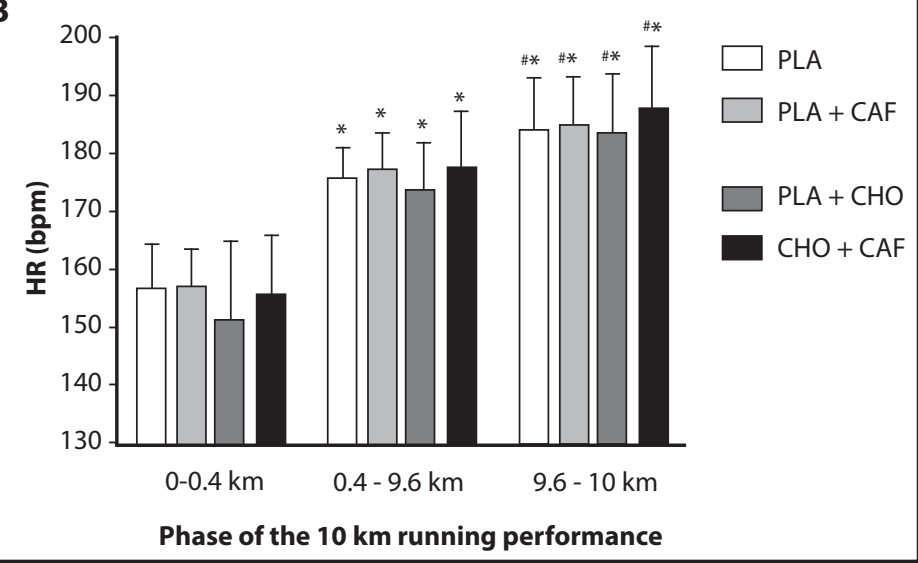

${ }^{*} P<0.001$ in relation to initial phase $(0-0.4 \mathrm{~km})$; $* P<0.001$ in relation to middle phase $(0.4-9.6 \mathrm{~km})$. 
The CAF is an ergogenic aid, widely used mainly in endurance events, which has demonstrated positive effects in the performance of most of the studies ${ }^{19,20}$, however in the present study no difference was observed in performance of 10-km after ingestion of CAF. Similar results were found by Bell, McLellan, \& Sabiston ${ }^{21}$ who evaluated CAF intake in 10- $\mathrm{km}$ on a treadmill showing that $4 \mathrm{mg} \cdot \mathrm{kg}^{-1}$ dosage did not affect performance (CAF: $46.0 \pm 2.8$ minutes; PLA: $46.8 \pm 3.2$ minutes). Although there was no statistical difference between PLA + CAF compared to PLA, 7 participants had a small improvement in performance (Figure 1A). This difference between the participants can be explained by individual factors, such as genetic factors that could explain this individual variability. Previous studies have suggested that inter-individual variations in polymorphisms of CYP1A2 and ADORA2A lead to different responses on running performance ${ }^{12,19}$. The first gene is responsible for metabolizing the caffeine in paraxanthine, theobromine, and theophylline; the second gene regulates the adenosine receptors ${ }^{12,19}$.

In addition, this small effect of supplementation on endurance performance is in agreement with the literature. In a recent systematic review and meta-analysis that verified the effect of acute caffeine ingestion on endurance performance, Southward et al. ${ }^{20}$ concluded that caffeine can be used as an effective ergogenic on environment like sport settings, where small increases in performance could lead to greater results.

Nonetheless, the role of $\mathrm{CHO}$ feeding as an ergogenic strategy to increase endurance capacity were consistently demonstrated in previous studies ${ }^{22,23}$. It has been demonstrated that during prolonged exercise the induced fatigue is often associated with muscle glycogen depletion and reduced blood glucose concentrations ${ }^{24}$ and, therefore, an increased pre-exercise muscle and liver glycogen concentrations are believed to be essential for optimal endurance performance. Previous studies have shown that the improvements in performance during prolonged (e.g. $>2$ h) and short (e.g. $<60$ minutes) exercise durations cannot be explained by the same mechanisms ${ }^{22,25}$.

However, during short exercise durations these ergogenic effect of $\mathrm{CHO}$ as a substrate point of view is unlikely to be influenced by the exogenous $\mathrm{CHO}$, since muscle glycogen stores is generally not limiting to performance ${ }^{22}$, when exercise durations are less than $\approx 60$ minutes $^{25}$. The finding of the present investigation further supports the notion that for exercises ranging for up to $\approx 60$ minutes, the demands are adequately met by the endogenous $\mathrm{CHO}$ stores and rather than providing addition benefits, exogenous $\mathrm{CHO}$ intake may have any further effect on endurance performance, as no statistical difference was observed for the group after supplementation and a slight improvement in 8 of the 15 participants after supplementation (Figure 1B), which could perhaps be more pronounced if the activity had a longer duration.

Studies that have verified the effect of CAF and $\mathrm{CHO}$ combined supplementation yield controversial results ${ }^{2,26,27}$. It is believed that one of the advantages of this combination would be the fact that during prolonged exercise, CAF could contribute to the final part of the performance due to its potential ergogenic effect of the stimulation of the central nervous system (CNS), reducing perceived exertion ${ }^{28}$, as demonstrated in previous studies that found improvement in performance after evaluating the combination of $\mathrm{CAF}$ and $\mathrm{CHO}^{26,27}$.
Despite the positive effects of the combination of $\mathrm{CHO}$ and $\mathrm{CAF}$ on performance, in the present study no improvement in 10-km performance was observed after the combined intake of $\mathrm{CHO}$ and $\mathrm{CAF}$, a similar result of literature studies ${ }^{2,26}$. The results of the present study reinforce the growing number of studies which found that combining multiple ingredient supplementation may not confer exactly greater benefit than isolated supplementation ${ }^{26,29}$

The ingestion of the supplement on this present study in the form of capsules may also have inhibited its potential ergogenic effect, as studies show benefits in performance only with the mouthwash of $\mathrm{CHO}$ and $\mathrm{CAF}$ due to initial activation of the mouth receptors that later activate the nervous system and the central nervous system (CNS) ${ }^{30,31}$. Perhaps the most efficient way of supplementing these substances for performance improvement would be in liquid form or in gums ${ }^{31}$.

The pacing strategy can be influenced by several factors, among them are the inventories of intramuscular energy substrates and metabolic alterations ${ }^{32}$. In the present study, a difference between the conditions for the pacing strategy was observed (Figure 2). For the PLA condition the participants of the present study adopted a more conservative strategy during the performance of $10-\mathrm{km}$. Such a strategy is called "constant" and is characterized by the maintenance or by a small change of velocity during the test ${ }^{33-35}$. This strategy seems to be more common for athletes with this profile (recreational). Previous studies that compared the race strategy adopted during a 10-km race between runners of different levels ${ }^{1,36}$, identified that lower-level athletes usually chosen the same "constant" strategy as observed in the present investigation for the PLA condition. The choice of this more conservative strategy can be explained by the fact that if the initial velocities are very high they can induce a large imbalance at the beginning of the exercise, which would harm the athlete for the rest of the race, which may induce a premature fatigue, making it impossible to maintain speed impairing the performance ${ }^{34}$.

For the conditions of caffeine supplementation (PLA+CAF, $(\mathrm{AF}+\mathrm{CHO})$, a "negative" strategy was observed during the 10-km running performance. This strategy is characterized by a fast start and with a later reduction in speed until the end of the performance ${ }^{33-35}$. Caffeine appears to stimulate a faster onset of performance, which may be related to its potential ergogenic effects, mainly the effect of the stimulant on the central nervous system (CNS), thus increasing alertness and reducing perceived exertion ${ }^{31}$. Bertuzzi et al. ${ }^{17}$, concluded after evaluating the contribution of some physiological and muscular variables for the pacing strategy adopted during 10-km running performance running, that the rating of perceived exertion is the variables that best explain the performance in the start phase $(0.4 \mathrm{~km})$ of the $10-\mathrm{km}$ running performance, and its reduction may have been responsible for making runners perceive a slower speed or effort than they actually are performing.

Different from caffeine, the carbohydrate appears to have an effect on the final outcome of the performance, since the pacing strategy adopted by participants in the PLA + CHO condition was a "J" strategy, characterized by a faster onset, then a reduction in the intermediate phase and with a greater increase of velocity at the end phase, being this one higher than the start phase $\mathrm{e}^{33-35}$. This high increase in speed at the end of the performance for this condition could be related to the greater availability of $\mathrm{CHO}$, which is the main energy substrate for high 
intensity exercise $e^{5,37}$. However future studies are needed to identify the associations of pacing strategy adopted and the availability of $\mathrm{CHO}$ during prolonged exercise durations like the 10-km running performance.

Although different running strategies were observed for each supplementation condition, at the end of the performance it was possible to observe an increase in velocity, a phenomenon known as "end spurt" or "final sprint"37. In the present study, it was found that all the conditions were more pronounced in the PLA + CHO condition.

Regarding the HR no difference was observed between the conditions (Figure 3B), there was only difference between the three phases of the performance for the same condition. This increase in HR over the course of performance, even with no statistical difference in velocity in some conditions, can be attributed to the increased metabolic demand imposed by the intensity of the activity ${ }^{38}$, as well as by extrinsic factors such as environmental temperature and hydration status of the participants ${ }^{39}$. In the end phase, an increase in HR was observed in both conditions, reaching the maximum values. This increase is related to sprint performed by runners to obtain a better result at the end of the race ${ }^{33,35,40}$.

\section{Conclusion}

In conclusion, the use of acute, isolated and combined $\mathrm{CAF}+\mathrm{CHO}$ supplementation had no influence in the final 10-km running performance, HRmax, for the group. However, performance improvement was observed in most participants when analyzing the results individually. In addition, supplementation was responsible for causing changes in the pacing strategy for recreational runners. These findings provide important insight into the specific conditions in which the $\mathrm{CAF}$ and $\mathrm{CHO}$ condition supplementation could be used as an ergogenic substance for some individuals. Thus, isolated and combined CAF+CHO supplementation strategies can be used as an important tactical advantage (i.e. pacing strategy) in 10-km running performance depending on the strategy previously chosen by the athletes.

\section{Conflict of interest}

The authors do not declare a conflict of interest.

\section{Bibliography}

1. Lima-Silva AE, Bertuzzi RC, Pires FO, Barros, RV, Gagliardi JF, Hammond J, et al. Effect of performance level on pacing strategy during a 10-km running race. Eur J Appl Physiol. 2010;108:1045-53.

2. Oberlin-Brown KT, Siegel R, Kilding AE, Laursen PB. Oral presence of carbohydrate and caffeine in chewing gum: independent and combined effects on endurance cycling performance. Int J Sports Physiol Perform. 2016;11:164-71.

3. Conger AS, Warren LG, Hardy AM, Mindy LMS. Does caffeine added to carbohydrate provide additional ergogenic benefit for endurance? Int J Sport Nutr Exerc Metab. 2011;21:71-84.

4. Schubert MM, Astorino TA. A systematic review of the efficacy of ergogenic aids for improving running performance. J Strength Cond Res. 2013;27:1699-707.

5. Mata F, Valenzuela PL, Gimenez J, Tur C, Ferreria D, Domínguez, et al. Carbohydrate availability and physical performance: physiological overview and practical recommendations. Nutrients. 2019;11:1084.

6. Rollo I, Willians C. Influence of ingesting a carbohydrate electrolyte solution before and during a 1-hr running performance test. Int J Sport Nutr Exerc Metab. 2009;19:645-58.
7. Cox GR, Desbrow B, Montgomery PG, Anderson ME, Bruce CR, Macrides TA, et al. Effect of different protocols of caffeine intake on metabolism and endurance performance. J Appl Physiol. 2002;93:990-99.

8. Wickham KA, Spriet LL. Administration of caffeine in alternate forms. Sports Med. 2018;48:79-91.

9. Tarnopolsky MA, Safdar A. The potential benefits of creatine and conjugated linoleic acid as adjuncts to resistance training in older adults. Appl Physiol Nutr Metab. 2008;33:213-27.

10. Goldstein ER, Ziegenfuss T, Kalman D, Kreider R, Campbell B, Wilborn C, et al. International society of sports nutrition position stand: caffeine and performance. J Int Soc Sports Nutr. 2010;7:2-15.

11. Clarke ND, Richardson DL, Thie J, Taylor R. Coffee ingestion enhances one-mile running race performance. Int J Sports Physiol Perform. 2018;13:789-94.

12. Marques AC, Jesus AA, Giglio BM, Marini AC, Lobo PCB, Mota JF, et al. Acute caffeinated coffee consumption does not improve time trial performance in an $800-\mathrm{m}$ run: a randomized, double-blind, crossover, placebo-controlled study. Nutrients. 2018;10:657.

13. Cureton KJ, Warren GL, Millard-Stafford ML, Wingo JE, Trilk J, Buyckx M. Caffeinated sports drink: ergogenic effects and possible mechanisms. Int J Sport Nutr Exerc Metab. 2007;17:35-55.

14. Yeo SE, Jentjens RL, Wallis GA, Jeukendrup AE. Caffeine increases exogenous carbohydrate oxidation during exercise. J App/ Physiol. 2005;99:844-50.

15. Acker-Hewitt TL, Shafer BM, Saunders MJ, Goh Q, Luden ND. Independent and combined effects of carbohydrate and caffeine ingestion on aerobic cycling performance in the fed state. Appl Physiol Nutr Metab. 2012;37:276-83.

16. Dolan P, Witherbee KE, Peterson KM, Kerksick CM. Effect of carbohydrate, caffeine, and carbohydrate + caffeine mouth rinsing on intermittent running performance in collegiate male lacrosse athletes. J Strength Cond Res. 2017;31:2473-79.

17. Bertuzzi R, Lima-Silva AE, Pires FO, Damasceno, MV, Bueno S, Pasqua LA, et al. Pacing strategy determinants during a 10-km running time trial: contributions of perceived effort, physiological, and muscular parameters. J Strength Cond Res. 2014;28:1688-96.

18. Lee C, Cheng C, Astorino TA, Lee CJ, Huang H, Chang W. Effects of carbohydrate combined with caffeine on repeated sprint cycling and agility performance in female athletes. J Int Soc Sports Nutr. 2014;11:2-12.

19. Pickering C, Grgic J. Caffeine and exercise: what next? Sports Med. 2019;49(7):1007-30.

20. Southward K, Rutherfurd-Markwick KJ, Ali A. The effect of acute caffeine ingestion on endurance performance: a systematic review and meta-analysis. Sports Med. 2018;48:1913-28.

21. Bell DG, McLellan TM, Sabiston CM. Effect of ingesting caffeine and ephedrine on 10-km run performance. Med Sci Sports Exerc. 2002;34:344-9.

22. Jeukendrup AE. Carbohydrate and exercise performance: the role of multiple transportable carbohydrates. Curr Opin Clin Nutr Metab Care. 2010;13:452-57.

23. McCarthy DG, Spriet LL. Performance effects of carbohydrate ingestion between bount of intense aerobic interval training. Int J Sports Physiol Perform. Epub ahead of print 12 June 2019. Doi: 10.1123/ijspp.2019-0239.

24. Jeukendrup AE. Carbohydrate intake during exercise and performance. Nutrition. 2004;20:669-77.

25. StellingwerffT, Cox GR. Systematic review: carbohydrate supplementation on exercise performance or capacity of varying durations. Appl Physio/ Nutr Metab. 2014;39:998-11.

26. Germaine M, Collins K, Shortall M. The effect of caffeine ingestion and carbohydrate mouth rinse on high-intensity running performance. Sports. 2019;7:63.

27. Miller B, O'Connor H, Orr R, Ruell P, Cheng HL, Chow CM. Combined caffeine and carbohydrate ingestion: effects on nocturnal sleep and exercise performance in athletes. Eur J Appl Physiol. 2014;114:2529-37.

28. Stear SJ, Castell LM, Burke LM, Spriet LL. BRSM reviews: A-Z of nutritional supplements: dietary supplements, sports nutrition foods and ergogenic aids for health and performance Part 6. Br J Sports Med. 2010;44:297-98.

29. Naderi A, Earnest CP, Lowery RP, Wilson JM, Willems MET. Co-ingestion of nutritional ergogenic aids and high-intensity exercise performance. Sport Med. 2016;46:1407-18.

30. Chambers ES, Bridge MW, Jones DA. Carbohydrate sensing in the human mouth: Effects on exercise performance and brain activity. J Physiol. 2009;587:1779-94

31. Devenney S, Mangan S, Shortall M, Collins K. Effects of carbohydrate mouth rinse and caffeine on high intensity interval running in a fed state. Appl Physiol Nutr Metab. 2017:43:517-21.

32. Jones AM, Wilkerson DP, DiMenna F, Fulford J, Poole DC. Muscle metabolic responses to exercise above and below the "critical power" assessed using 31P-MRS. Am J Physiol Regul Integr Comp Physiol. 2008;294:585-93.

33. Abbiss CR, Laursen PB. Describing and understanding pacing strategies during athletic competition. Sports Med. 2008;38:239-52. 
34. Do Carmo EC, Gil S, Bueno S, Pasque LA, Lima-silva AE, Bertuzzi RC. Risco de fadiga prematura, percepção subjetiva de esforço e estratégia de prova durante uma corrida de 10 km. Rev Bras Educ Fís Esporte. 2015;29:197-05.

35. Tucker R, Lambert MI, Noakes TD. An analysis of pacing strategies during men's worldrecord performances in track athletics. Int J Sports Physiol Perform. 2006;1:233-45.

36. Manoel FA, Kravchychyn ACP, Alves JCC, Machado FA. Influência do nível de performance na estratégia de ritmo de corrida em prova de $10 \mathrm{~km}$ de corredores recreacionais. Rev Bras Educ Fís Esporte. 2015;29:355-60

37. Noakes TD. Physiological models to understand exercise fatigue and the adaptations that predict or enhance athletic performance. Scand J Med Sci Sports. 2000;10:123-45.
38. Petit MA, Nelson CM, Rhodes EC. Comparison of a mathematical model to predict 10-km performance from the Conconi Test and ventilatory threshold measurements. Can J Appl Physiol. 1997;22:562-72.

39. Bertuzzi RSM, Nakamura FY, Rossi LC, Kiss MAPD, Franchini E. Independência temporal das respostas do esforço percebido e da frequência cardíaca em relação à velocidade de corrida na simulação de uma prova de $10 \mathrm{~km}$. Rev Bras Med Esporte. 2006;21:179-83.

40. Joseph T, Johnson B, Battista RA, Wright G, Dodge C, Porcari JP, et al. Perception of fatigue during simulated competition. Med Sci Sports Exerc. 2008:40:381-6. 